\title{
Changes in patient weight and the impact of antidiabetic therapy during the first 5 years after diagnosis of diabetes mellitus
}

\author{
N. de Fine Olivarius • A. H. Andreasen • V. Siersma • \\ B. Richelsen $\cdot$ H. Beck-Nielsen
}

Received: 11 November 2005 / Accepted: 2 May 2006 / Published online: 14 July 2006

(C) Springer-Verlag 2006

\begin{abstract}
Aims/hypothesis It is generally thought difficult for type 2 diabetic patients to lose weight. We monitored changes in patients' weight during the first 5 years after diabetes diagnosis in relation to initiation of antidiabetic treatment. Subjects and methods Data from 711 newly diagnosed diabetic patients aged 40 or over were analysed with a random-effect linear-regression model. Patients were included consecutively from a well-defined patient list in general practice.

Results In 245 patients whose only treatment was advice on diet, an initial weight loss of 6 to $7 \mathrm{~kg}$ was largely
\end{abstract}

Electronic Supplementary Material Supplementary material is available for this article at http://dx.doi.org/10.1007/s00125-006$0328-\mathrm{y}$ and is accessible for authorised users.

N. de Fine Olivarius $(\bowtie) \cdot$ A. H. Andreasen $\cdot$ V. Siersma

The Research Unit for General Practice,

University of Copenhagen,

Øster Farimagsgade 5, P.O. Box 2099,

DK-1014 Copenhagen K, Denmark

e-mail: no@gpract.ku.dk

\section{A. H. Andreasen · V. Siersma}

Department of Biostatistics, Institute of Public Health,

University of Copenhagen,

Copenhagen, Denmark

\author{
A. H. Andreasen \\ Research Centre for Prevention and Health, \\ Glostrup, Copenhagen County, Denmark \\ B. Richelsen \\ Medical Department C, Århus Sygehus, \\ Århus University Hospital, \\ Århus, Denmark \\ H. Beck-Nielsen \\ Medical Department M, Odense University Hospital, \\ Odense, Denmark
}

maintained over 5 years. Patients receiving metformin $(n=86)$ or sulfonylureas $(n=330)$ maintained an average weight loss of 2 to $4 \mathrm{~kg}$ that was dependent on age and sex. Patients' weight did not change on initiation of treatment with sulfonylureas or metformin. Over 5 years, median $\mathrm{HbA}_{1 \mathrm{c}}$ increased from 7.0 to $7.8 \%$ (reference range 5.4$7.4 \%$ ) in the diet-alone group. $\mathrm{HbA}_{1 \mathrm{c}}$ was approximately 1 percentage point higher for most of the other treatment groups.

Conclusions/interpretation In newly diagnosed type 2 diabetic patients, long-term weight loss was common and weight loss was not affected by sulfonylurea treatment. The measurements in the study are taken from treatment results achieved in the general population of diabetic patients, who are rarely treated in secondary care and seldom the subject of research; the results thus indicate that weight reduction is a practicable treatment in diabetic patients.

Keywords Diet therapy $\cdot$ Family practice .

Follow-up studies $\cdot$ Metformin $\cdot$ Sulfonylureas .

Type 2 diabetes mellitus $\cdot$ Weight $\cdot$ Weight gain

\author{
Abbreviations \\ ESM Electronic supplementary material \\ UKPDS UK Prospective Diabetes Study
}

\section{Introduction}

Obesity is associated with insulin resistance and an increased risk of developing type 2 diabetes mellitus [1-3]. Lifestyle changes, including weight reduction, may result in a clinically important reduction of the incidence of diabetes $[4,5]$, coronary heart disease [6] and even mortality [7] in 
non-diabetic persons at high risk or in diabetic patients. It is commonly observed that treatment of type 2 diabetic patients with sulfonylureas [8-10] or insulin [10-12] is associated with weight gain. This effect of sulfonylureas and insulin could possibly aggravate the insulin-resistance syndrome associated with type 2 diabetes [2, 13, 14] and thereby counteract the otherwise beneficial effects of these agents. In contrast to insulin and sulfonylureas, treatment with metformin seems to be associated with weight reduction [8, 15] or weight stabilisation [9, 16].

It is widely held that lasting weight loss is difficult to achieve [17]. In type 2 diabetic patients this view is chiefly founded on studies concerned with selected groups of patients and on intervention studies implementing step-up treatment with specific antidiabetic drugs. In the United Kingdom Prospective Diabetes Study (UKPDS) the initial weight loss was regained after 2 years of treatment in the insulin and sulfonylurea randomisation arms [18]. The perspective of such studies needs to be widened by results from studies using individualised treatment schemes allowing for doctors' and patients' influence on choice of treatment modality.

In a population-based sample of type 2 diabetic patients receiving structured individualised care by primary-care physicians [19], we examined the changes in weight during the first 5 years after diabetes diagnosis in relation to initiation of antidiabetic pharmacological treatment.

\section{Subjects and methods}

\section{Study population}

At the end of 1988, 474 general practitioners volunteered to take part in the Danish study, 'Diabetes Care in General Practice'. Before the study started, the general practitioners were randomised to an intervention and a comparison group [19]. Weight measurements over the whole period were collected in the intervention group only, so this study is confined to 711 patients in this group (Fig. 1). Of these, 19 patients started insulin treatment within 180 days of diagnosis. Insulin was discontinued for two of these patients during the observation period. Thus, 694 (97.6\%) patients were considered to have type 2 diabetes.

The intervention

Follow-up every 3 months and annual screening for diabetic complications were supported by sending a questionnaire to the general practitioner 1 month before the next expected consultation [19]. The general practitioner was also requested to define, together with the patient, the best possible goals, within three predefined categories of good, acceptable and poor control, for blood glucose, $\mathrm{HbA}_{1 \mathrm{c}}(\leq 7.0, \leq 8.5$ and $>8.5 \%)$, diastolic blood pressure $(\leq 90, \leq 100$ and $>100 \mathrm{mmHg})$, total cholesterols $(\leq 6.0, \leq 7.0$ and $>7.0 \mathrm{mmol} / \mathrm{l})$ and fasting total triglycerides $(\leq 2.0, \leq 5.0$ and $>5.0 \mathrm{mmol} / \mathrm{l})$. At each quarterly consultation, the general practitioner was asked to compare the achievements with the goal and consider changing either goal or treatment accordingly. In overweight patients, the general practitioner was prompted to get agreement on a small, realistic weight reduction, write this down and to follow up on this. However, a specific relative bodyweight was not striven for. In Denmark, routine care of patients with type 2 diabetes is usually given by general practitioners in ordinary consultations and not in disease management sessions run by nurses.

The general practitioners were introduced to possible solutions to therapeutic problems through six annual halfday seminars, annual descriptive feedback reports on individual patients, and folders and leaflets for doctors and patients. Generally, the importance of diet was stressed and doctors were recommended to postpone, if possible, the start of antidiabetic drugs until at least 3 months after diagnosis to observe the effect of a possible weight loss. It was suggested that the general practitioners recommend increased physical exercise and simple diet rules: increase complex carbohydrate to at least $50 \%$ of the diet, and in particular increase water-soluble fibre, reduce fat content to a maximum of $30 \%$, reduce alcohol intake, and eat five or six meals a day. At study start the intervention doctors described their access to a dietician: private dietician $(3 \%)$, only through referral to a diabetes clinic (42\%) and no access at all (55\%). In cases of persistent hyperglycaemia, metformin was recommended for patients who were overweight by clinical judgement, and glipizide or glibenclamide was suggested for patients with normal weight. In patients $\geq 70$ years, tolbutamide was given preference. If the goal for blood glucose was not met, a combination of metformin and a sulfonylurea was recommended as the last step before starting insulin.

On 26 September 1995, the protocol-based final followup examinations were initiated in both groups and the intervention was terminated.

The protocol was approved by the ethics committee for Copenhagen and Frederiksberg, and informed consent was obtained from all patients.

\section{Measurements}

Patients were weighed without shoes and outer garments by the general practitioner on the scales in his/her practice at diagnosis and at $98.7 \%$ of the annual examinations and $95.5 \%$ of the 3 -monthly consultations. 


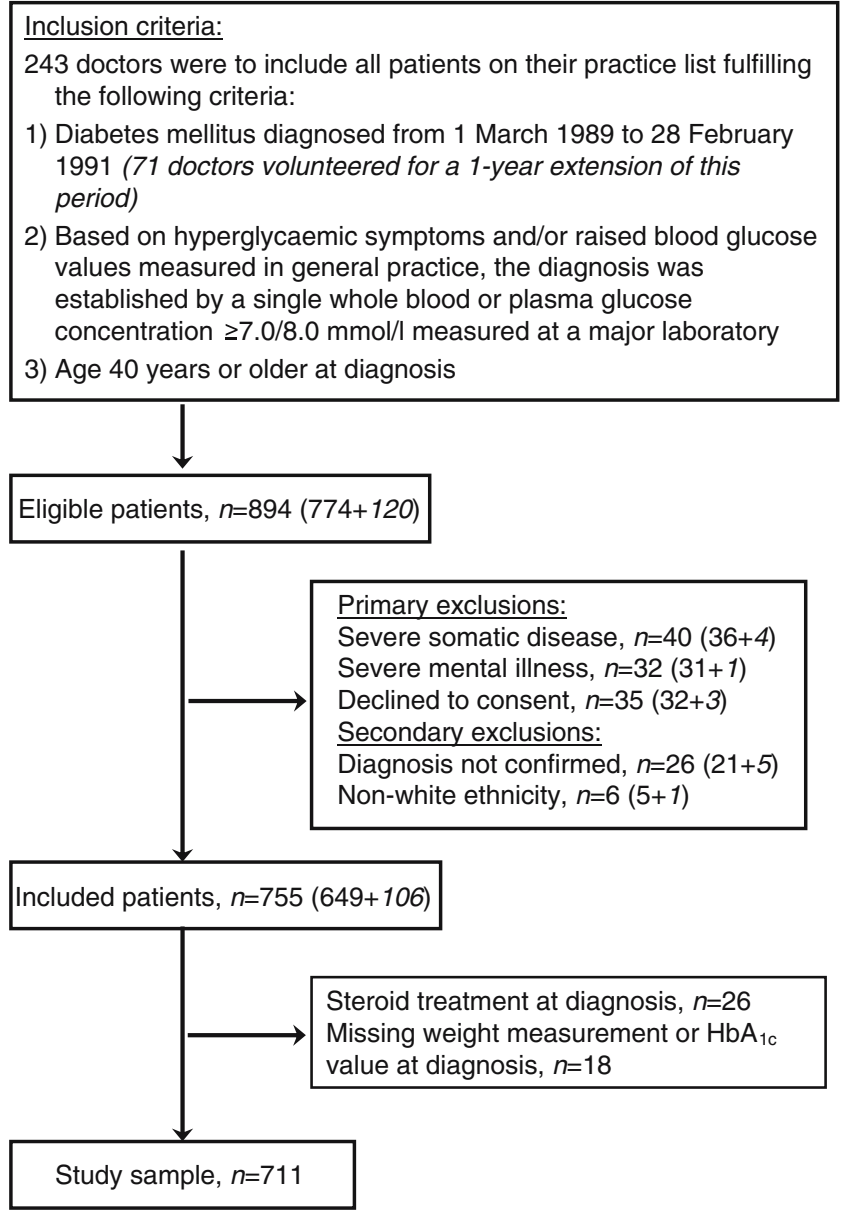

Fig. 1 Flow of participants through the study. The numbers of patients included during the 1-year extension of the 2-year inclusion period for

Fasting blood samples were drawn at diagnosis and at annual examinations. Fraction of $\mathrm{HbA}_{1 \mathrm{c}}$ was determined at Odense University Hospital by ion exchange HPLC (reference interval 5.4-7.4\%).

The general practitioner reported on the 3-monthly questionnaires whether treatment with oral antidiabetic agents or insulin had been initiated or changed. The exact type and dosage of the medication were reported on the annual questionnaires.

\section{Statistical analyses}

Because of observed sex differences (Table 1), we did separate analyses for men and women. The course of $\mathrm{HbA}_{1 \mathrm{c}}$ relative to the first pharmacological treatment was described by connecting the median values of the firstmeasured $\mathrm{HbA}_{1 \mathrm{c}}$ for each patient in each of the 1-year intervals after diabetes diagnosis.

The course of bodyweight and the effect of initiation of antidiabetic pharmacological treatment on this course was analysed in a random-effect model [20-22]. The data show that many patients experience a weight loss after diagnosis until the second or third quarterly consultation, after which weight seems to stabilise or increase slightly. Utilising this information, the course of bodyweight for an individual was modelled as piecewise linear, consisting of an intercept at diagnosis, a linear weight loss within the first year after diagnosis, and a linear weight regain tendency thereafter. We investigated models with a variety of breakpoints in the first year after diagnosis. A model with a breakpoint at 5 months was selected, as the residual plot for this model was the most favourable. On initiation of antidiabetic pharmacological treatment a change in weight regain tendency was allowed for in the model. The longitudinal information on bodyweight was subsequently censored at the end of follow-up, at death, exclusion or last study examination, or when a second antidiabetic pharmacological treatment was initiated. The weight at diagnosis, the drop thereafter, and the following weight regain tendency are different for each patient. These individual characteristics, however, are not the topic of analysis and regarded as normally distributed random variables in the mixed model. Furthermore, all components of the piecewise linear curve were allowed to depend linearly on age and $\mathrm{HbA}_{1 \mathrm{c}}$ at diagnosis and the first pharmacological treatment; only the possible change in weight regain tendency at initiation of pharmacological treatment did not depend on $\mathrm{HbA}_{1 \mathrm{c}}$ at diagnosis. The above implies a modelling of the average individual course of bodyweight relative to age, sex, $\mathrm{HbA}_{1 \mathrm{c}}$ at diagnosis and first antidiabetic treatment. The modelled average courses of individual bodyweight for selected values of covariates are represented graphically (Figs. 2 and 3). The number of men/women who contributed to the model with weight measurements in the period after 1, 2, 3, 4 and 5 years after diabetes diagnosis is $344 / 313,308 / 289$, 264/251, 200/209 and 126/146. $p$ values are from $F$-tests assessing a significant difference for different values of the covariate for that specific weight course component. A detailed description of the model is contained in the Electronic supplementary material (ESM).

\section{Results}

Patient characteristics are shown in Table 1. The male: female ratio was $1.16(382 / 329)$, and there are important sex differences. The median diagnostic plasma glucose was $13.6 \mathrm{mmol} / \mathrm{l}$. The median length of the follow-up period was 1,843 days (range 4-2,757 days). On 26 September 1995, 155 patients had died and 12 had been excluded. Of the remaining 544 patients, 501 were re-examined at the final follow-up examination (Table 2). A considerable weight loss was maintained among those treated with metformin, sulfonylureas and diet alone at 5-year follow- 
Table 1 Characteristics of study population and treatment according to antidiabetic treatment

\begin{tabular}{|c|c|c|c|c|c|c|c|c|c|}
\hline \multirow[t]{2}{*}{ Antidiabetic treatment } & \multicolumn{3}{|c|}{ Number of patients } & \multicolumn{3}{|c|}{ Age at diabetes diagnosis (years) } & \multicolumn{3}{|c|}{ BMI at diabetes diagnosis $\left(\mathrm{kg} / \mathrm{m}^{2}\right)$} \\
\hline & Males & Females & Total & Males & Females & $p$ & Males & Females & $p$ \\
\hline \multicolumn{10}{|c|}{ First pharmacological treatment } \\
\hline Metformin & 41 & 45 & 86 & $\begin{array}{l}58.1 \\
(51.7-64.0)\end{array}$ & $\begin{array}{l}62.3 \\
(54.6-68.4)\end{array}$ & 0.037 & $\begin{array}{l}31.5 \\
(29.4-33.6)\end{array}$ & $\begin{array}{l}33.7 \\
(30.7-37.9)\end{array}$ & 0.012 \\
\hline Sulfonylureas & 174 & 156 & 330 & $\begin{array}{l}65.0 \\
(54.6-72.9)\end{array}$ & $\begin{array}{l}69.6 \\
(58.5-76.4)\end{array}$ & 0.003 & $\begin{array}{l}28.5 \\
(25.9-30.7)\end{array}$ & $\begin{array}{l}28.8 \\
(25.7-32.9)\end{array}$ & 0.25 \\
\hline Metformin+sulfonylureas & 16 & 9 & 25 & $\begin{array}{l}56.4 \\
(50.8-63.7)\end{array}$ & $\begin{array}{l}68.1 \\
(66.3-71.9)\end{array}$ & 0.12 & $\begin{array}{l}30.8 \\
(26.8-35.5)\end{array}$ & $\begin{array}{l}33.6 \\
(30.9-35.9)\end{array}$ & 0.24 \\
\hline Insulin & 12 & 13 & 25 & $\begin{array}{l}70.2 \\
(65.4-77.3)\end{array}$ & $\begin{array}{l}53.0 \\
(46.8-72.5)\end{array}$ & 0.11 & $\begin{array}{l}29.6 \\
(23.4-30.4)\end{array}$ & $\begin{array}{l}22.3 \\
(20.0-27.2)\end{array}$ & 0.034 \\
\hline Diet alone $^{\mathrm{a}}$ & 139 & 106 & 245 & $\begin{array}{l}63.8 \\
(54.6-72.1)\end{array}$ & $\begin{array}{l}69.0 \\
(59.6-75.9)\end{array}$ & 0.003 & $\begin{array}{l}29.8 \\
(26.6-33.0)\end{array}$ & $\begin{array}{l}29.3 \\
(25.6-33.1)\end{array}$ & 0.40 \\
\hline All patients & 382 & 329 & 711 & $\begin{array}{l}63.5 \\
(54.0-71.5)\end{array}$ & $\begin{array}{l}67.8 \\
(57.6-75.7)\end{array}$ & $<0.0001$ & $\begin{array}{l}29.3 \\
(26.3-32.1)\end{array}$ & $\begin{array}{l}29.7 \\
(26.1-33.6)\end{array}$ & 0.29 \\
\hline \multirow[t]{2}{*}{ Antidiabetic treatment } & \multicolumn{3}{|c|}{$\begin{array}{l}\mathrm{HbA}_{1 \mathrm{c}} \text { at diabetes diagnosis } \\
(\%)^{\mathrm{b}}\end{array}$} & \multicolumn{3}{|c|}{$\begin{array}{l}\text { Time from diagnosis until initiation } \\
\text { of first antidiabetic pharmacological } \\
\text { treatment (years) }\end{array}$} & \multicolumn{3}{|c|}{$\begin{array}{l}\text { Duration of first antidiabetic } \\
\text { pharmacological treatment (years) }\end{array}$} \\
\hline & Males & Females & $p$ & Males & Females & $p$ & Males & Females & $p$ \\
\hline \multicolumn{10}{|c|}{ First pharmacological treatment } \\
\hline Metformin & $\begin{array}{l}10.0 \\
(8.6-11.2)\end{array}$ & $\begin{array}{l}9.8 \\
(8.8-11.6)\end{array}$ & 0.83 & $\begin{array}{l}1.4 \\
(0.3-2.6)\end{array}$ & $\begin{array}{l}0.9 \\
(0.3-2.9)\end{array}$ & 0.64 & $\begin{array}{l}2.0 \\
(1.0-3.3)\end{array}$ & $\begin{array}{l}2.2 \\
(1.2-3.6)\end{array}$ & 0.52 \\
\hline Sulfonylureas & $\begin{array}{l}10.4 \\
(8.9-11.8)\end{array}$ & $\begin{array}{l}9.9 \\
(8.4-11.6)\end{array}$ & 0.067 & $\begin{array}{l}1.0 \\
(0.3-2.2)\end{array}$ & $\begin{array}{l}1.2 \\
(0.3-2.4)\end{array}$ & 0.34 & $\begin{array}{l}2.5 \\
(1.2-3.9)\end{array}$ & $\begin{array}{l}2.9 \\
(1.4-4.2)\end{array}$ & 0.18 \\
\hline Metformin+sulfonylureas & $\begin{array}{l}10.6 \\
(8.6-12.7)\end{array}$ & $\begin{array}{l}10.0 \\
(9.2-12.8)\end{array}$ & 0.98 & $\begin{array}{l}0.7 \\
(0.4-2.6)\end{array}$ & $\begin{array}{l}0.3 \\
(0.1-0.3)\end{array}$ & 0.066 & $\begin{array}{l}2.1 \\
(1.1-3.2)\end{array}$ & $\begin{array}{l}2.7 \\
(1.8-5.3)\end{array}$ & 0.16 \\
\hline Insulin & $\begin{array}{l}8.2 \\
(7.5-10.6)\end{array}$ & $\begin{array}{l}9.5 \\
(8.3-11.7)\end{array}$ & 0.38 & $\begin{array}{l}0.02 \\
(0-1.0)\end{array}$ & $\begin{array}{l}0.3 \\
(0.0-0.3)\end{array}$ & 0.81 & $\begin{array}{l}4.0 \\
(1.7-5.7)\end{array}$ & $\begin{array}{l}5.0 \\
(4.2-5.6)\end{array}$ & 0.38 \\
\hline Diet alone $^{\mathrm{a}}$ & $\begin{array}{l}8.7 \\
(7.5-10.8)\end{array}$ & $\begin{array}{l}8.8 \\
(7.5-10.2)\end{array}$ & 0.99 & - & - & - & - & - & - \\
\hline All patients & $\begin{array}{l}9.9 \\
(8.2-11.4)\end{array}$ & $\begin{array}{l}9.4 \\
(8.1-11.5)\end{array}$ & 0.47 & $\begin{array}{l}1.0 \\
(0.3-2.2)\end{array}$ & $\begin{array}{l}1.0 \\
(0.3-2.3)\end{array}$ & 0.90 & $\begin{array}{l}2.4 \\
(1.1-3.8)\end{array}$ & $\begin{array}{l}2.9 \\
(1.4-4.4)\end{array}$ & 0.033 \\
\hline
\end{tabular}

Data are numbers or medians (interquartile range). $p$ values are from Wilcoxon tests

${ }^{a}$ The diet-alone group included all patients treated with diet alone throughout the study

${ }^{\mathrm{b}}$ Reference range $5.4-7.4 \%$

up. Patients with glucosuria at 5-year follow-up had smaller average weight loss than patients without glucosuria (Table 2). Only glucosuric patients treated with a combination of metformin and sulfonylureas had a relatively larger weight loss (data not shown). In a linear-regression analysis the weight at 5 -year follow-up was predicted by weight at diagnosis $(p<0.0001)$, age $(p<0.0001)$, sex $(p=0.044)$ and treatment at 5 -year follow-up $(p<0.0001)$, but not by glucosuria at 5 -year follow-up $(p=0.28)$. Compared with patients receiving sulfonylureas the diet and insulin group attained a weight loss $(p=0.001)$ and a weight gain $(p=0.006)$, respectively. Patients receiving metformin $(p=0.83)$ or metformin and sulfonylurea $(p=0.35)$ did not experience a weight change different from the sulfonylurea group.
For the remaining analyses, data from all patients were included from the day of diagnosis until the last follow-up examination done while they were on the first antidiabetic treatment, which was either antidiabetic drugs or diet for those patients on diet alone throughout the study. The median time spent on first pharmacological antidiabetic treatment was not less than 2 years for any treatment (Table 1). First antidiabetic treatment was not associated with sex ( $\chi^{2}$-test, $\left.p=0.45\right)$, but for both sexes first treatment varied with age at diagnosis (Wilcoxon test, $p=0.001$ for men; $p=0.009$ for women) and BMI at diagnosis $(p=0.0002$ and 0.0001 , respectively) (Table 1 ).

We modelled changes in weight after diabetes diagnosis according to first antidiabetic treatment. The model is summarised in Table 3, which shows that the intercept of 
Fig. 2 Examples of the course of bodyweight developments as described by the model according to age, sex and first antidiabetic pharmacological treatment, sulfonylureas (blue), metformin (green), metformin and sulfonylurea (yellow), insulin (red), or diet alone (black). a Males, 40-64 years. b Females, 40-64 years. c Males, 65+ years. d Females, $65+$ years. $\mathrm{HbA}_{1 \mathrm{c}}$ was set at $10.0 \%$ in all panels. The first and second vertical lines indicate changes in weight course 5 months after diabetes diagnosis and any change at initiation of antidiabetic pharmacological treatment if this occurs 2 years after diabetes diagnosis, respectively
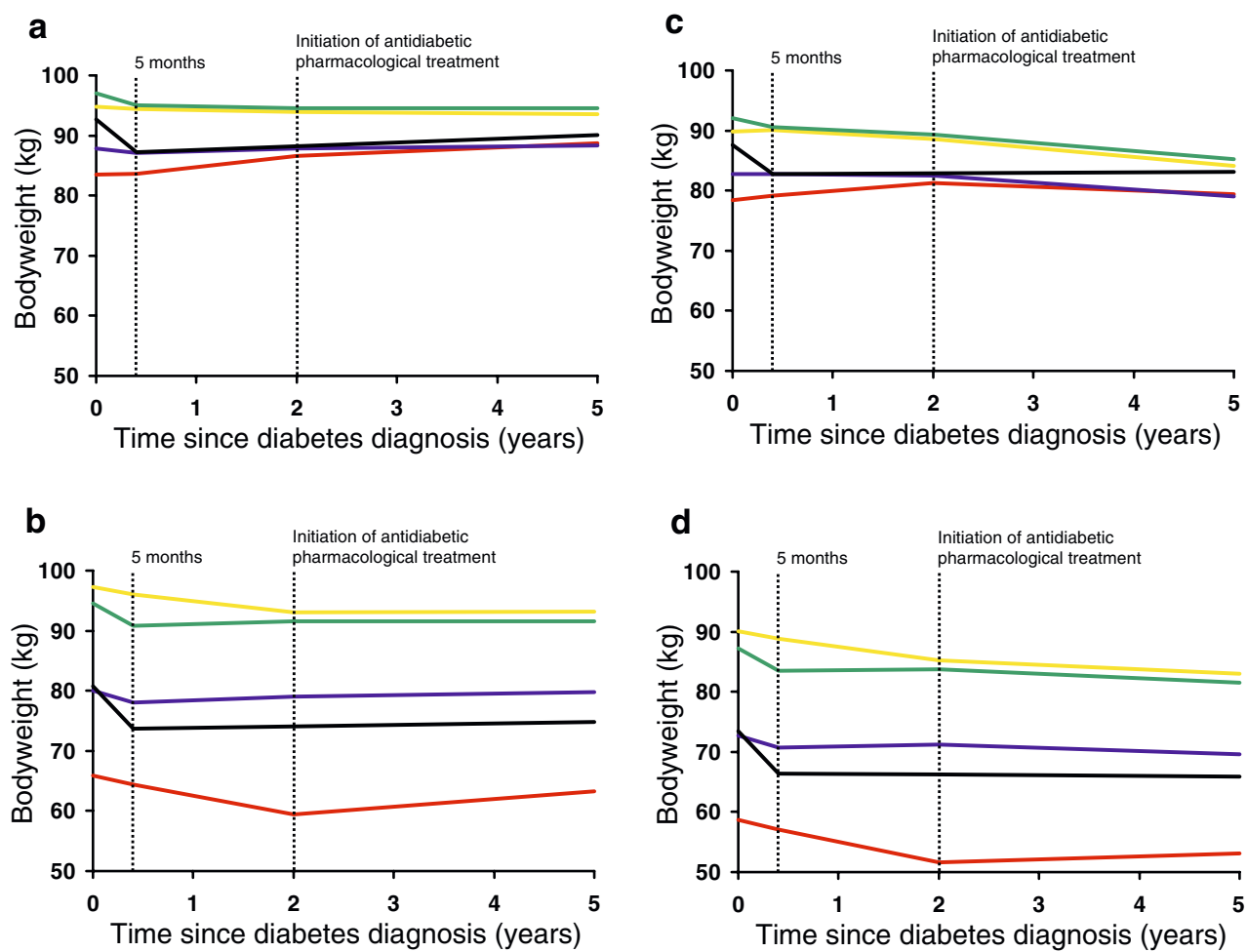

the expected weight course, i.e. the weight at diagnosis, varies with age and first treatment. Similarly, the average weight loss tendency during the first 5 months after diagnosis depends on first antidiabetic treatment and for men also on $\mathrm{HbA}_{1 \mathrm{c}}$, and the average weight regain tendency from 5 months after diagnosis depends on age and first antidiabetic treatment. Figure 2 displays the ageand sex-related features of the model including statistically non-significant effects. Initiation of first pharmacological antidiabetic treatment is assumed to occur 2 years after diabetes diagnosis in this visualisation of the model. The initial and long-term average weight loss is most pro- nounced in the diet group, in accord with Table 2. Both weight variability and achieved weight loss seem to be greater for women than for men (Table 3, Fig. 2).

The effect of $\mathrm{HbA}_{1 \mathrm{c}}$ is small and statistically nonsignificant for females, so this effect is illustrated in Fig. 3 for males only. For all treatment modalities, weight curves for patients with relatively high $\mathrm{HbA}_{1 \mathrm{c}}$ values lie above and have a more ascending slope than weight curves for patients with relatively low $\mathrm{HbA}_{1 \mathrm{c}}$ measurements (Fig. 3, Table 3).

The model in Table 3 includes terms for a change in weight regain tendency at the time of initiation of first drug

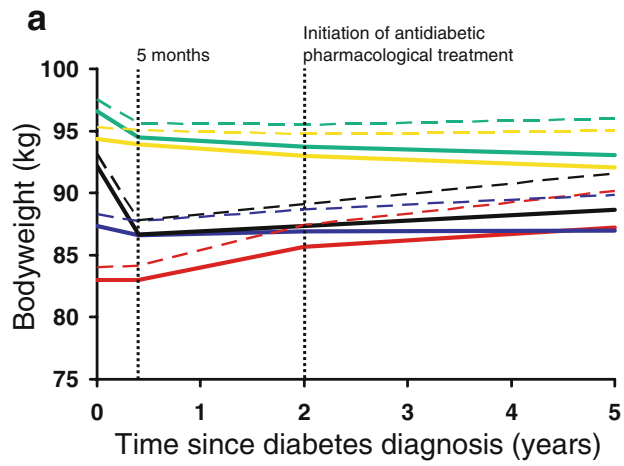

Fig. 3 Examples of the course of bodyweight developments (males only) as described by the model according to $\mathrm{HbA}_{1 \mathrm{c}}$, age and first antidiabetic pharmacological treatment, sulfonylureas (blue), metformin (green), metformin and sulfonylurea (yellow), insulin (red), or diet alone (black). a $40-64$ years. b $65+$ years. $\mathrm{HbA}_{1 \mathrm{c}}=8.0 \%$ (solid lines). $\mathrm{HbA}_{1 \mathrm{c}}=12.0 \%$

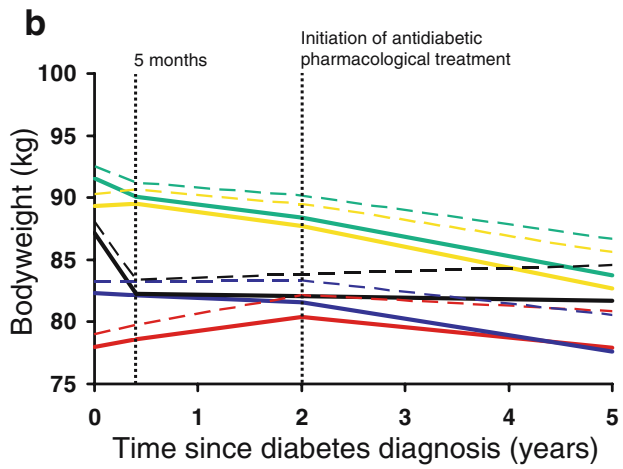

(broken lines). Reference range of $\mathrm{HbA}_{1 \mathrm{c}}: 5.4-7.4 \%$. The first and second vertical lines indicate changes in weight course 5 months after diabetes diagnosis and any change at initiation of antidiabetic pharmacological treatment if this occurs 2 years after diabetes diagnosis, respectively 
Table 2 Bodyweight at diabetes diagnosis and 5-year follow-up according to treatment modality or glucosuria at 5-year follow-up

\begin{tabular}{|c|c|c|c|c|c|}
\hline $\begin{array}{l}\text { Antidiabetic treatment or presence of } \\
\text { glucosuria at } 5 \text {-year follow-up }\end{array}$ & $\begin{array}{l}\text { Number of } \\
\text { patients }\end{array}$ & $\begin{array}{l}\text { Bodyweight at diabetes } \\
\text { diagnosis }(\mathrm{kg})\end{array}$ & $\begin{array}{l}\text { Bodyweight at 5-year } \\
\text { follow-up }(\mathrm{kg})\end{array}$ & $\begin{array}{l}\text { Weight change since } \\
\text { diabetes diagnosis }(\mathrm{kg})\end{array}$ & $p$ \\
\hline \multicolumn{6}{|l|}{ Antidiabetic treatment } \\
\hline Metformin & 43 & 92.5 & 88.2 & $-4.3(-6.3 ;-2.3)$ & $<0.0001$ \\
\hline Sulfonylureas & 180 & 81.8 & 78.9 & $-2.9(-3.9 ;-1.9)$ & $<0.0001$ \\
\hline Metformin+sulfonylureas & 70 & 88.8 & 86.8 & $-2.0(-3.7 ;-0.4)$ & 0.014 \\
\hline Insulin & 56 & 79.4 & 80.0 & $0.5(-1.0 ; 2.1)$ & 0.48 \\
\hline Diet alone & 152 & 84.1 & 78.7 & $-5.4(-6.5 ;-4.2)$ & $<0.0001$ \\
\hline All patients & 501 & 84.1 & 80.9 & $-3.3(-3.9 ;-2.6)$ & $<0.0001$ \\
\hline All patients with glucosuria ${ }^{a}$ & 107 & 88.3 & 86.5 & $-1.8(-3.0 ;-0.5)^{\mathrm{b}}$ & 0.005 \\
\hline All patients without glucosuria ${ }^{a}$ & 381 & 82.9 & 79.4 & $-3.5(-4.2 ;-2.8)^{\mathrm{b}}$ & $<0.0001$ \\
\hline
\end{tabular}

Data are numbers or means $\left(95 \%\right.$ CIs). $p$ values are from a $t$-test for $\mathrm{H}_{\mathrm{o}}$ : mean=zero

${ }^{a}$ In 13 patients information about glucosuria at 5-year follow-up was missing

${ }^{\mathrm{b}} p=0.022, t$-test of whether the weight change is the same for patients with and without glucosuria

treatment and these terms were not significant in the reduced model either (see the ESM). Consequently we do not expect any change in average regain at the time of initiation of first drug treatment, and the bending of the curves in Figs. 2 and 3 at initiation of first antidiabetic pharmacological treatment is not statistically significant.

The median daily doses of the first pharmacological treatment agents were (range in parenthesis): metformin: 1,000 (500-2,000) mg, glibenclamide: $3.5(0.875-21) \mathrm{mg}$, glipizide: 5 (2.5-25) $\mathrm{mg}$, tolbutamide: $750(250-2,000) \mathrm{mg}$, insulin: 27 (10-48) IE. Only 19 patients received sulfonylureas other than those mentioned above. During the period of first treatment the median doses increased only for tolbutamide (to $1,000 \mathrm{mg}$ ) and glipizide (to $7.5 \mathrm{mg}$ ).

Plots of the changes in $\mathrm{HbA}_{1 \mathrm{c}}$ after diabetes diagnosis show relatively favourable glucose status in the diet group and relatively high glucose levels in the few men treated with insulin (Fig. 4). The comparatively low initial $\mathrm{HbA}_{1 \mathrm{c}}$ values in the insulin group are because many of these patients had been hospitalised when insulin treatment started and were enrolled in the study at a relatively late stage.

\section{Discussion}

We found that a sustained weight loss is common in type 2 diabetic patients up to 5 years after diabetes diagnosis, and that initiation of treatment with sulfonylurea was not followed by a change in average weight-regain tendency.

In type 2 diabetes the interrelationships between the metabolic state, antidiabetic treatment and changes in weight are complex. On the one hand, obesity is a strong risk factor for the development of type 2 diabetes [1, 3], but in newly diagnosed diabetic patients a high level of blood glucose is associated with glucosuria and thereby loss of energy and weight. On the other hand, improving glycaemic control, e.g. through antidiabetic pharmacological treatment, may reverse a weight loss [23], but weight loss is in itself associated with reduced insulin resistance and improved glucose metabolism [14]. Caught in this delicate causal web we can only suggest various possible interpretations of our findings.

Weight loss due to calorie loss in glucosuria

The sustained weight loss observed in the present study may possibly be due to undertreatment, relatively poor glycaemic control and consequent energy loss in glucosuria. We found, however, that patients with relatively high $\mathrm{HbA}_{1 \mathrm{c}}$ measurements at diagnosis actually had weight trajectories that were above those of patients with relatively low $\mathrm{HbA}_{1 \mathrm{c}}$ values (Fig. 3). Furthermore, patients with glucosuria at 5-year follow-up had smaller average weight loss than patients without glucosuria (Table 2). These findings are more in line with the explanation that weight loss is followed by improved glycaemic control. Even small weight losses are associated with a pronounced improvement of glucose tolerance [24, 25]. Weight loss and improved glycaemia are also more readily achieved in subjects with diabetes of relatively short duration [26, 27].

The quality of the glycaemic control in our study may seem relatively poor when viewed in the context of present day intentions, but it is on a level with that of UKPDS; in the UKPDS intervention group the average $\mathrm{HbA}_{1 \mathrm{c}}$ dropped to normal during the first year, but then began to rise to reach approximately $7.2 \%$ after 6 years [10]. In our study the average $\mathrm{HbA}_{1 \mathrm{c}}$ after 6 years was $8.5 \%$ [19]. The reference range of $\mathrm{HbA}_{1 \mathrm{c}}$ was $4.5-6.2 \%$ in UKPDS and $5.4-7.4 \%$ in our study. The development of glycaemic control in our 
Table 3 Estimation of fixed effects in the mixed model for course of bodyweight after diabetes diagnosis

\begin{tabular}{|c|c|c|c|c|}
\hline \multirow[t]{2}{*}{ Explanatory variable } & \multicolumn{2}{|l|}{ Males } & \multicolumn{2}{|l|}{ Females } \\
\hline & Estimate & $p^{\mathrm{a}}$ & Estimate & $p^{\mathrm{a}}$ \\
\hline Weight at diagnosis & 85.20 & & 73.98 & \\
\hline Age & & 0.0016 & & 0.0001 \\
\hline 40-64 years & 5.03 & & 7.26 & \\
\hline $65+$ years & 0 & & 0 & \\
\hline $\mathrm{HbA}_{1 \mathrm{c}}$ & 24.08 & 0.48 & -4.78 & 0.89 \\
\hline First antidiabetic treatment & & 0.0008 & & 0.0001 \\
\hline Sulfonylureas & -4.82 & & -0.74 & \\
\hline Metformin & 4.41 & & 13.74 & \\
\hline Metformin+sulfonylurea & 2.18 & & 16.56 & \\
\hline Insulin & -9.15 & & -14.88 & \\
\hline Diet alone & 0 & & 0 & \\
\hline Slope of weight curve $(s)$ & -12.96 & 0.0006 & -17.83 & 0.0001 \\
\hline$s \times$ Age & & 0.30 & & 0.95 \\
\hline 40-64 years & -1.52 & & -0.10 & \\
\hline $65+$ years & 0 & & 0 & \\
\hline$s \times \mathrm{HbA}_{1 \mathrm{c}}$ & 9.73 & 0.040 & 1.68 & 0.76 \\
\hline$s \times$ First antidiabetic treatment & & 0.0001 & & 0.0001 \\
\hline Sulfonylureas & 11.80 & & 12.45 & \\
\hline Metformin & 8.46 & & 8.38 & \\
\hline Metformin+sulfonylurea & 12.64 & & 14.46 & \\
\hline Insulin & 13.70 & & 13.90 & \\
\hline Diet alone & 0 & & 0 & \\
\hline Change in slope after 5 months $\left(c_{5}\right)$ & 12.05 & 0.003 & 17.54 & 0.0001 \\
\hline$c_{5} \times$ Age & & 0.18 & & 0.87 \\
\hline $40-64$ years & 2.08 & & 0.26 & \\
\hline $65+$ years & 0 & & 0 & \\
\hline$c_{5} \times$ First antidiabetic treatment & & 0.0001 & & 0.0001 \\
\hline Sulfonylureas & -12.02 & & -12.00 & \\
\hline Metformin & -9.36 & & -8.13 & \\
\hline Metformin+sulfonylurea & -13.64 & & -16.59 & \\
\hline Insulin & -12.45 & & -17.23 & \\
\hline Diet alone & 0 & & 0 & \\
\hline Change in slope at initiation of first antidiabetic pharmacological treatment $\left(c_{\mathrm{A}}\right)$ & -0.98 & 0.36 & -0.84 & 0.17 \\
\hline$c_{\mathrm{A}} \times$ Age & & 0.22 & & 0.48 \\
\hline $40-64$ years & 0.78 & & 0.37 & \\
\hline $65+$ years & 0 & & 0 & \\
\hline$c_{\mathrm{A}} \times$ First antidiabetic treatment & & 0.91 & & 0.16 \\
\hline Sulfonylureas & 0 & & 0 & \\
\hline Metformin & 0.46 & & -0.02 & \\
\hline Metformin+sulfonylurea & 0.45 & & 2.38 & \\
\hline Insulin & -0.95 & & 4.81 & \\
\hline Diet alone & 0 & & 0 & \\
\hline
\end{tabular}

Data are explanatory variables for the mean in the full model. Age and $\mathrm{HbA}_{1 \mathrm{c}}$ are as measured at diabetes diagnosis

${ }^{\mathrm{a}}$ Wald test based on restricted maximum likelihood estimation

study thus seems comparable with that of the intervention arm of UKPDS, even though the median plasma glucose concentration at presentation in our study was $13.8 \mathrm{mmol} / \mathrm{l}$ [19] compared with $11.3 \mathrm{mmol} / \mathrm{l}$ in UKPDS [28].

Weight loss due to successful treatment

Promoting long-term weight loss in type 2 diabetic patients is difficult [29, 30]. Even in successful intensive behaviour- modification programmes a pattern of weight regain is the predominant outcome [31, 32], and diabetic patients demonstrate even poorer weight loss maintenance than their nondiabetic peers [33]. However, one early study of diet counselling to newly diagnosed diabetic patients showed that a weight loss of $9 \mathrm{~kg}$ was maintained over 6 years [34]. Although it is tempting to ascribe the benign weight course in our study to the treatment model, there is no evidence to suggest that primary-care practitioners in general have 
a

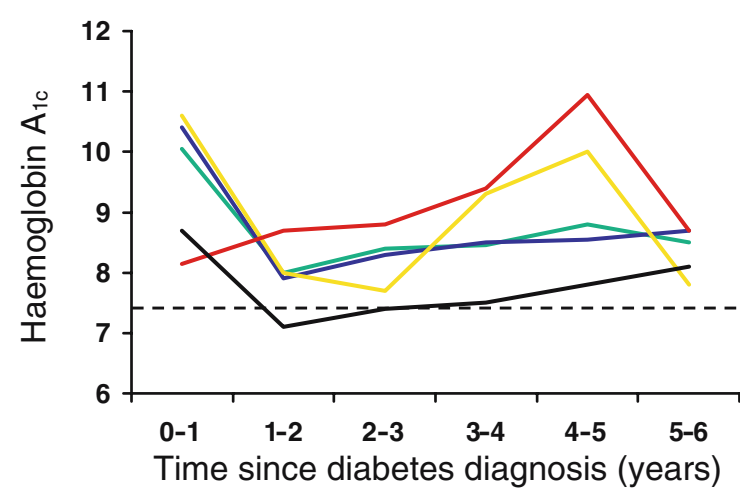

b

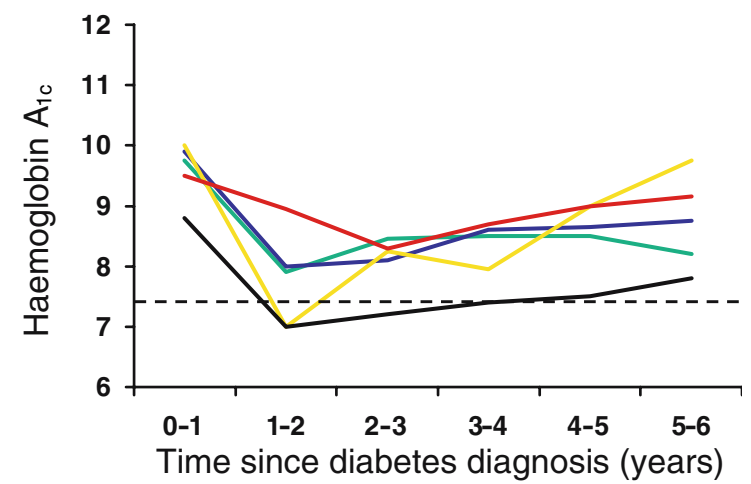

Fig. 4 The course of $\mathrm{HbA}_{1 \mathrm{c}}$ from the time of diagnosis according to sex and first antidiabetic pharmacological treatment, sulfonylureas (blue), metformin (green), metformin and sulfonylurea (yellow), insulin (red), or diet alone (black). a Males. b Females. Values are medians. The upper limit of the reference range of $\mathrm{HbA}_{1 \mathrm{c}}(5.4-7.4 \%)$ is indicated by the horizontal dotted line

special competence in obtaining weight loss among their patients $[35,36]$. But general practitioners may be more likely to give weight-control advice to their diabetic patients than to patients who are obese but without risk factors [37].

In the present study, doctors largely followed the recommendations given to them, supplying metformin to the most obese patients and sulfonylureas to patients with lower bodyweight (Fig. 2). In contrast to other experimental studies $[9,10,16]$, we observed no change in the course of weight after initiation of sulfonylurea treatment (Table 3). Weight loss is a common concomitant of the onset of metformin treatment $[9,10,16]$, a finding which we cannot confirm either (Table 3). These results were possibly affected by the doctors' considerations about who would benefit from which drug treatment in our individualised treatment model. Our study shows the average weight development for patients selected in daily practice to be treated with diet alone, oral agents or insulin. The factors influencing this treatment choice, besides age, sex and $\mathrm{HbA}_{1 \mathrm{c}}$, are unclarified in our analyses. At the yearly seminars the intervention doctors were repeatedly encour- aged to increase the dose of oral agents to the maximum if needed. Nevertheless the observed doses were low compared with other studies. It is possible that the general practitioners in our study unwittingly found a better balance between the dosage of sulfonylurea and its side-effects, e.g. weight gain. A more aggressive high-dose treatment would probably have resulted in a steeper increase in bodyweight, as was observed in UKPDS. Whether such a treatment model would have given better glycaemic control than our individualised model is an open question.

Weight loss and the natural history of type 2 diabetes

The well-defined background population in each general practice, the unchanged inclusion activity during the inclusion period and the small number of exclusions all suggest that our patients are representative of the general population of newly diagnosed diabetic patients in this age group in Denmark. Furthermore, 6 years after diagnosis, only $17 \%$ of the surviving patients had ever been treated at a diabetes clinic [19]. The high average age in the present study in comparison with UKPDS may primarily be ascribed to differences in inclusion criteria for age (2565 years inclusive in UKPDS and 40 years or over in the present study).

In contrast to the belief that few individuals succeed in maintaining long-term weight loss, a relatively large proportion of the general population experience weight losses and maintain these for at least 1 year [38]. Although it is unclear whether the prevalence and maintenance of successful weight loss are higher in the general community than in the research clinic [20], we wish to propose that our study reflects treatment results obtained in the general population of type 2 diabetic patients rarely treated in secondary care and rarely participants in clinical trials.

Further study limitations

We make full use of the longitudinal structure of data, and our statistical model provides a visualisation of the changes in weight (Fig. 2), which confirms and extends our crosssectional analysis of surviving patients from the 5-year follow-up examination (Table 2). We did not, however, include $\mathrm{HbA}_{1 \mathrm{c}}$ measurements from the follow-up period as such a model would be difficult to interpret because of the unclarified causal relationships mentioned above.

In the present study, data come from the intervention group of a randomised trial, but it is unlikely that the observed weight changes are a result of the specific intervention tested in this study. Firstly, the comparison group had experienced the same average weight loss as the intervention group at the final 6-year follow-up examination [19]. Secondly, treatment with diet alone was equally 
common in the intervention and comparison groups, and metformin was the only drug used more frequently in the intervention group (24 vs $15 \%$ ) [19]. The median value of $\mathrm{HbA}_{1 \mathrm{c}}$ at 6-year follow-up, however, was lower for intervention patients than for comparison patients $(8.0$ vs $8.5 \%)$.

\section{Conclusions and implications}

We had two major findings in this group of diabetic patients observed for 5 years after diabetes diagnosis: (1) a sustained weight loss was common and patients with a pronounced weight loss were often treated with metformin or diet alone, and (2) there was no evidence of a change in course of weight on initiation of treatment with any antidiabetic medication, including sulfonylureas, even though acceptable glycaemic control was achieved. The study was conducted in a clinical setting allowing doctors to select patients for specific antidiabetic treatments according to the development of the disease, the recommendations of clinical guidelines, and patient preferences. However, specific reasons for the weight loss cannot be deduced from our observational study. The important message for doctors and patients is that weight reduction is a practicable treatment in newly diagnosed diabetic patients even when patients are given sulfonylureas.

Acknowledgements We gratefully acknowledge the contributions of the participating patients and general practitioners. We are indebted to N. Keiding, Department of Biostatistics, University of Copenhagen for his supervision of the statistical modelling. For technical support we thank L. Bergsøe. The main funding was from The Danish Medical Research Council, The Danish Research Foundation for General Practice, The Health Insurance Foundation, The Danish Ministry of Health, Novo Nordisk Farmaka Denmark Ltd, and The Pharmacy Foundation.

Duality of interest There is no duality of interest to declare.

\section{References}

1. Colditz GA, Willett WC, Rotnitzky A, Manson JE (1995) Weight gain as a risk factor for clinical diabetes mellitus in women. Ann Intern Med 122:481-486

2. Ludvik B, Nolan JJ, Baloga J, Sacks D, Olefsky J (1995) Effect of obesity on insulin resistance in normal subjects and patients with NIDDM. Diabetes 44:1121-1125

3. Ford ES, Williamson DF, Liu S (1997) Weight change and diabetes incidence: findings from a national cohort of US adults. Am J Epidemiol 146:214-222

4. Knowler WC, Barrett-Connor E, Fowler SE et al (2002) Reduction in the incidence of type 2 diabetes with lifestyle intervention or metformin. N Engl J Med 346:393-403

5. Tuomilehto J, Lindstrom J, Eriksson JG et al (2001) Prevention of type 2 diabetes mellitus by changes in lifestyle among subjects with impaired glucose tolerance. N Engl J Med 344: $1343-1350$

6. Ellat-Adar S, Eldar M, Goldbourt U (2005) Association of intentional changes in body weight with coronary heart disease event rates in overweight subjects who have an additional coronary risk factor. Am J Epidemiol 161:352-358

7. Williamson DF, Thompson TJ, Thun M et al (2000) Intentional weight loss and mortality among overweight individuals with diabetes. Diabetes Care 23:1499-1504

8. Josephkutty S, Potter JM (1990) Comparison of tolbutamide and metformin in elderly diabetic patients. Diabet Med 7:510-514

9. Hermann LS, Schersten B, Bitzen PO et al (1994) Therapeutic comparison of metformin and sulfonylurea, alone and in various combinations. A double-blind controlled study. Diabetes Care 17:1100-1109

10. UKPDS Group (1998) Intensive blood-glucose control with sulphonylureas or insulin compared with conventional treatment and risk of complications in patients with type 2 diabetes (UKPDS 33). UK Prospective Diabetes Study Group. Lancet 352:837-853

11. Groop L, Widen E, Franssila-Kallunki A et al (1989) Different effects of insulin and oral antidiabetic agents on glucose and energy metabolism in type 2 (non-insulin-dependent) diabetes mellitus. Diabetologia 32:599-605

12. Birkeland KI, Rishaug U, Hanssen KF, Vaaler S (1996) NIDDM: a rapid progressive disease. Results from a long-term, randomised, comparative study of insulin or sulphonylurea treatment. Diabetologia 39:1629-1633

13. Ferrannini E, Natali A, Bell P et al (1997) Insulin resistance and hypersecretion in obesity. European Group for the Study of Insulin Resistance (EGIR). J Clin Invest 100:1166-1173

14. Rosenfalck AM, Hendel H, Rasmussen MH et al (2002) Minor long-term changes in weight have beneficial effects on insulin sensitivity and beta-cell function in obese subjects. Diabetes Obes Metab 4:19-28

15. DeFronzo RA, Goodman AM (1995) Efficacy of metformin in patients with non-insulin-dependent diabetes mellitus. The Multicenter Metformin Study Group. N Engl J Med 333:541-549

16. Clarke BF, Campbell IW (1977) Comparison of metformin and chlorpropamide in non-obese, maturity-onset diabetics uncontrolled by diet. BMJ 2:1576-1578

17. No authors listed (1998) Clinical guidelines on the identification, evaluation, and treatment of overweight and obesity in adults - the evidence report. National Institutes of Health. Obes Res 6(Suppl 2): 51S-209S

18. Wright A, Burden ACF, Paisey RB, Cull CA, Holman RR (2002) Sulfonylurea inadequacy-efficacy of addition of insulin over 6 years in patients with type 2 diabetes in the UK Prospective Diabetes Study (UKPDS 57). Diabetes Care 25:330-336

19. Olivarius NdF, Beck-Nielsen H, Andreasen AH, Horder M, Pedersen PA (2001) Randomised controlled trial of structured personal care of type 2 diabetes mellitus. BMJ 323:970-975

20. Bartlett SJ, Faith MS, Fontaine KR, Cheskin LJ, Allison DB (1999) Is the prevalence of successful weight loss and maintenance higher in the general community than the research clinic? Obes Res 7:407-413

21. Cnaan A, Laird NM, Slasor P (1997) Using the general linear mixed model to analyse unbalanced repeated measures and longitudinal data. Stat Med 16:2349-2380

22. Diggle PJ, Liang KY, Zeger SL (1994) Analysis of longitudinal data. Clarendon, Oxford

23. Welle S, Nair KS, Lockwood D (1988) Effect of a sulfonylurea and insulin on energy expenditure in type II diabetes mellitus. J Clin Endocrinol Metab 66:593-597

24. Wing RR, Klein R, Moss SE (1990) Weight gain associated with improved glycemic control in population-based sample of subjects with type I diabetes. Diabetes Care 13:1106-1109 
25. Blackburn GI (1996) How much weight loss? In: Angel A et al (eds) Progress in obesity research. John Libbey, London, pp 621-625

26. Nagulesparan M, Savage PJ, Bennion LJ, Unger RH, Bennett PH (1981) Diminished effect of caloric restriction on control of hyperglycemia with increasing known duration of type-II diabetes mellitus. J Clin Endocrinol Metab 53:560-568

27. Franz MJ, Monk A, Barry B et al (1995) Effectiveness of medical nutrition therapy provided by dietitians in the management of noninsulin-dependent diabetes-mellitus - a randomized, controlled clinical trial. J Am Diet Assoc 95:1009-1017

28. UKPDS Group (1991) UK Prospective Diabetes Study. VIII. Study design, progress and performance. Diabetologia 34:877-890

29. Brown SA, Upchurch S, Anding R, Winter M, Ramirez G (1996) Promoting weight loss in type II diabetes. Diabetes Care 19:613-624

30. Manning RM, Jung RT, Leese GP, Newton RW (1995) The comparison of four weight reduction strategies aimed at overweight diabetic patients. Diabet Med 12:409-415

31. Eriksson KF, Lindgarde F (1991) Prevention of type 2 (noninsulin-dependent) diabetes mellitus by diet and physical exercise. The 6-year Malmo feasibility study. Diabetologia $34: 891-898$
32. Kramer FM, Jeffery RW, Forster JL, Snell MK (1989) Long-term follow-up of behavioral treatment for obesity: patterns of weight regain among men and women. Int $\mathrm{J}$ Obes 13:123-136

33. Guare JC, Wing RR, Grant A (1995) Comparison of obese NIDDM and nondiabetic women - short-term and long-term weight loss. Obes Res 3:329-335

34. Hadden DR, Blair ALT, Wilson EA et al (1986) Natural history of diabetes presenting age 40-69 years-a prospective-study of the influence of intensive dietary therapy. Q J Med 59:579-598

35. Kinmonth AL, Woodcock A, Griffin S, Spiegal N, Campbell MJ (1998) Randomised controlled trial of patient centred care of diabetes in general practice: impact on current wellbeing and future disease risk. The Diabetes Care From Diagnosis Research Team. BMJ 317:1202-1208

36. Moore H, Summerbell CD, Greenwood DC, Tovey P, Griffiths J (2003) Improving management of obesity in primary care: cluster randomised trial. BMJ 327:1085-1088

37. Simkin-Silverman LR, Gleason KA, King WC et al (2005) Predictors of weight control advice in primary care practices: patient health and psychosocial characteristics. Prev Med 40:71-82

38. McGuire MT, Wing RR, Hill JO (1999) The prevalence of weight loss maintenance among American adults. Int $\mathrm{J}$ Obes 23:1314-1319 